\title{
Silent sinus syndrome
}

INSERM

\section{Source}

INSERM. (1999). Orphanet: an online rare disease and orphan drug data base. Silent sinus syndrome. ORPHA:71276

Silent sinus syndrome is characterised by adult-onset progressive enophthalmos due to collapse of some or all of the maxillary sinus walls. 